\title{
Etoposide increases equilibrative nucleoside transporter 1 activity and fluorothymidine uptake: Screening of 60 cytotoxic agents
}

\author{
EUN JUNG LEE ${ }^{1}$ and SEUNG JIN LEE ${ }^{1,2}$ \\ ${ }^{1}$ Institute for Innovative Cancer Research, Asan Institute for Life Sciences, Asan Medical Center, \\ ${ }^{2}$ University of Ulsan, College of Medicine, Songpa-gu, Seoul 138-736, Republic of Korea
}

Received July 27, 2012; Accepted September 17, 2012

DOI: 10.3892/or.2012.2172

\begin{abstract}
Equilibrative nucleoside transporter 1 (ENT1) is a major regulator for the uptake of $\left[{ }^{18} \mathrm{~F}\right]$ fluorothymidine $\left(\left[{ }^{18} \mathrm{~F}\right] \mathrm{FLT}\right)$, a promising positron emission tomography tracer for treatment monitoring. Various antimetabolites such as 5-fluorouracil often increase ENT1 activity and $\left[{ }^{18} \mathrm{~F}\right] \mathrm{FLT}$ uptake (flare) in spite of cell death. However, it has not yet been defined which agents induce $\left[{ }^{18} \mathrm{~F}\right] \mathrm{FLT}$ flare and what is the role of $\left[{ }^{18} \mathrm{~F}\right] \mathrm{FLT}$ flare in cell viability. Sixty cytotoxic agents from the LOPAC1280 library were screened for ENT1 activity in HeLa cells which predominantly express ENT1, and topoisomerase inhibitors (i.e., aurintricarboxylic acid, idarubicin, camptothecin and etoposide) were identified as potent inducers of ENT1 activity. The changes in ENT1 activity were closely correlated with $\left[{ }^{3} \mathrm{H}\right] \mathrm{FLT}$ uptake (Spearman's correlation coefficient, $\mathrm{r}=0.66 ; \mathrm{P}<0.01)$. Etoposide significantly increased ENT1 activity and $\left[{ }^{3} \mathrm{H}\right] \mathrm{FLT}$ uptake accompanying cell cycle arrest at $\mathrm{S} / \mathrm{G} 2 / \mathrm{M}$ phase and the increase in TK1 expression and activity in both ENT1-low expressing HT29 and ENT1high expressing MDA-MB-231 cells. The inhibition of ENT1 activity by dipyridamol or S-(p-nitrobenzyl)-6-thioinosine repressed the etoposide-induced cell death in HeLa cells, whereas it induced no changes in the other cell lines. In conclusion, etoposide is identified as a potent inducer for ENT1 activity and $\left[{ }^{3} \mathrm{H}\right] \mathrm{FLT}$ uptake. The role of ENT1 activity by etoposide was cell-type dependent, which requests caution for the application of ENT1-mediated $\left[{ }^{18} \mathrm{~F}\right] \mathrm{FLT}$ flare for treatment monitoring.
\end{abstract}

\section{Introduction}

$\left[{ }^{18} \mathrm{~F}\right]$ Fluorothymidine $\left(\left[{ }^{18} \mathrm{~F}\right] \mathrm{FLT}\right)$ is a promising positron emission tomography (PET) tracer for monitoring tumor size

\footnotetext{
Correspondence to: Dr Seung Jin Lee, Institute for Innovative Cancer Research, Asan Institute for Life Sciences, Asan Medical Center, University of Ulsan, College of Medicine, Olympic-ro 43-gil, Songpa-gu, Seoul 138-736, Republic of Korea

E-mail: sj_lee@amc.seoul.kr
}

Key words: equilibrative nucleoside transporter 1, fluorothymidine, thymidine kinase 1, etoposide, LOPAC1280 library
(1). As $\left[{ }^{18} \mathrm{~F}\right] \mathrm{FLT}$ uptake is regulated by the salvage pathway for DNA synthesis involving equilibrative nucleoside transporter 1 (ENT1) and thymidine kinase 1 (TK1), the decrease in cell proliferation by drugs eventually reduces $\left[{ }^{18} \mathrm{~F}\right] \mathrm{FLT}$ uptake. Yet, recent studies have reported that some cytotoxic agents induce an initial increase in $\left[{ }^{18} \mathrm{~F}\right] \mathrm{FLT}$ uptake (known as $\left[{ }^{18} \mathrm{~F}\right] \mathrm{FLT}$ flare) during cell death. These chemotherapy agents include antimetabolites, such as gemcitabine, 5-fluorouracil (5-FU), methotrexate and capecitabine (2-6). The mechanism underlying chemotherapy-induced $\left[{ }^{18} \mathrm{~F}\right] \mathrm{FLT}$ flare may differ based on treatment schedules. Acute exposure to 5-FU induces the redistribution of ENT1 to the plasma membrane, whereas prolonged treatment with 5-FU increases the activity of ENT1 and TK1, along with $S$ phase arrest $(7,8)$. However, not all cytotoxic agents targeting DNA or inducing $\mathrm{S}$ phase arrest provoke $\left[{ }^{18} \mathrm{~F}\right] \mathrm{FLT}$ flare. For example, cisplatin induces DNA damage by crosslinking, which does not increase FLT uptake $(2,9,10)$. To date, no individualized evaluation of cytotoxic agents for $\left[{ }^{18} \mathrm{~F}\right] \mathrm{FLT}$ flare has been undertaken.

ENT1 is the main nucleoside transporter responsible for FLT uptake, as it is widely expressed in mammalian cells and tissues (11). It bi-directionally transports purine and pyrimidine nucleosides in a sodium-independent manner (12). ENT1 differs from ENT2 in that it is sensitive to the inhibitor S-(pnitrobenzyl)-6-thioinosine (NBTI) analogues. ENT1 activity is increased at the transcriptional level during $\mathrm{S}$ phase (13). It is also rapidly regulated at the post-transcriptional level via $\mathrm{PKC} / \varepsilon$, which converts it to the active and available form at the plasma membrane (14). Studies on the pharmacological regulation of ENT1 have focused on the downregulation of ENT1 activity by cardioprotective agents, such as dilazep, draflazine and dipyridamole, and by cytotoxic agents, including immunosuppressive, anticancer, and antiviral compounds $(15,16)$. Screening with protein kinase inhibitors showed that inhibitors of tyrosine kinases, protein kinase $\mathrm{C}$, cyclin-dependent kinase, mTOR and p38 MAPK selectively decrease ENT1 and inhibit cell proliferation. The pharmacological mechanisms that increase ENT1 activity and lead to $\left[{ }^{18} \mathrm{~F}\right] \mathrm{FLT}$ flare have not yet been examined.

Here, we aimed to identify pharmacologically active agents that increase ENT1 activity, and to investigate their effects on FLT uptake and cell proliferation. We screened 60 cytotoxic compounds from the LOPAC1280 library, which regulate apoptosis, cell cycle progression, DNA intercalation and DNA 
metabolism, and which may be involved in the regulation of cell viability or FLT metabolism (Table I). We also investigated the role of ENT1 activation for cytotoxic agent-induced cell death through screening. The induction of ENT1 activity and its role in cell death was confirmed in three types of cell lines with etoposide which was identified in this screening for the first time.

\section{Materials and methods}

Materials. HeLa, HT29 and MDA-MB-231 cells were obtained from the American Type Culture Collection (Rockville, MD). $\left[{ }^{3} \mathrm{H}\right] \mathrm{S}$-(p-Nitrobenzyl)-6-thioinosine $\left(\left[{ }^{3} \mathrm{H}\right] \mathrm{NBTI}\right)(10 \mathrm{Ci} / \mathrm{mmol})$ and $\left[\right.$ methyl $\left.-{ }^{3} \mathrm{H}\right] \mathrm{FLT}(9.5 \mathrm{Ci} / \mathrm{mmol})$ were obtained from Moravek Biochemicals (Brea, CA). $\left[\right.$ methyl $\left.-{ }^{3} \mathrm{H}\right]$ thymidine (9.5 Ci/mmol) was from Perkin-Elmer (Waltham, MA). The LOPAC1280 library and other reagents were purchased from Sigma-Aldrich (St. Louis, MO) for screening ENT1 activity. Etoposide (E1383) used in confirmatory experiments of ENT1 activity was additionally purchased from Sigma-Aldrich.

Cell culture, treatment and preparation. Cells were maintained in RPMI-1640 containing 10\% fetal bovine serum, $10 \mathrm{U} / \mathrm{ml}$ penicillin and $10 \mu \mathrm{g} / \mathrm{ml}$ streptomycin at $37^{\circ} \mathrm{C}$ in a humidified atmosphere with $5 \% \mathrm{CO}_{2}$. For screening, all of the agents were used initially at a concentration of $10 \mu \mathrm{M}$, but some agents that induced dramatic cell death within $24 \mathrm{~h}$ at $10 \mu \mathrm{M}$ were used at a reduced concentration ( $1 \mu \mathrm{M}$ for $\beta$-lapachone, CHM-1 and mitoxantrone; $0.5 \mu \mathrm{M}$ for idarubicin). Cell lysates were prepared as described previously (7). Protein content was determined using the Bradford assay (Bio-Rad, Hercules, CA).

ENT1 activity in the plasma membrane. The number of $\left[{ }^{3} \mathrm{H}\right]$ NBTI binding sites/cell was determined according to Perumal et al (8). To determine the $\mathrm{Kd}$ and $\mathrm{B}_{\max }$ values for each cell line, $1 \times 10^{6}$ cells were incubated with Hank's buffered salt solution containing $\left[{ }^{3} \mathrm{H}\right] \mathrm{NBTI}$ at a concentration of $0.12,0.2,0.47$, $0.94,1.88,3.75,7.50$ or $15 \mathrm{nM}$ for $1 \mathrm{~h}$ under gentle agitation. In a parallel series of samples, $20 \mu \mathrm{M}$ S-(4-nitrobenzyl)-6thioguanosine (NBTG) was included for the calculation of specific binding. After washing with $\mathrm{Na}^{+}$-containing buffer, cells were resuspended in lysis buffer. The radioactivity of the lysates was measured in a liquid scintillation counter (Perkin-Elmer). Screening was performed with $\left[{ }^{3} \mathrm{H}\right]$ NBTI at 4.6-fold higher than the $\mathrm{Kd}$ value of HeLa cells $(3.75 \mathrm{nM})$ to economize the amount of isotope. Confirmatory studies were conducted for etoposide using $10 \mathrm{nM}\left[{ }^{3} \mathrm{H}\right] \mathrm{NBTI}$, which is 6- to 15 -fold higher than the Kd value of all the cell lines. Screening was repeatedly performed in five sets, with 10 agents/set $(n \geq 4)$. In every set, the vehicle and 5-FU were included as internal controls $(n=15)$.

Cell viability. Cells were plated at a density of $2 \times 10^{3}$ cells/ well in 96-well plates, incubated overnight, and exposed to each drug for $72 \mathrm{~h}$ at the same concentration used for the screening of ENT1 activity. Cell viability was examined using the 3-(4,5-dimethylthiazol-2-yl)-5-(3-carboxymethoxyphenyl)2-(4-sulfophenyl)-2H-tetrazolium (MTS) assay according to the manufacturer's instructions (Promega, Madison, WI). Three independent experiments were performed, each of which was performed in triplicate. $\left[{ }^{3} H\right] F L T$ uptake assay. Twenty-four hours after seeding in 6 -well plates at $3 \times 10^{5}$ cells/well, exponentially growing cells were exposed to agents for $24 \mathrm{~h}$. The media were then removed and replaced with $1 \mathrm{ml}$ fresh medium containing $\left[{ }^{3} \mathrm{H}\right] \mathrm{FLT}$ and incubated for a further $2 \mathrm{~h}$. The radioactivity in the cells and the supernatants was measured in a liquid scintillation counter (Perkin-Elmer). An aliquot of each cell fraction was used for cell counting by trypan blue exclusion. $\left[{ }^{3} \mathrm{H}\right] \mathrm{FLT}$ uptake was calculated as $100 \times \mathrm{CPM}_{\text {cells }} /\left(\mathrm{CPM}_{\text {cells }}+\mathrm{CPM}_{\text {supernatants }} / 1 \times 10^{5}\right.$ viable cells. All experiments were independently repeated four times.

Flow cytometric analysis. Cells treated with vehicle or etoposide for $24 \mathrm{~h}$ were trypsinized, fixed in $70 \%$ ethanol, stained with propidium iodide, and subjected to flow cytometry (Becton Dickinson, San Jose, CA). Data obtained from the Particle Analysis System were processed with ModFit LT software (Verity Software House). All experiments were independently repeated three times.

Measurement of TK1 activity. TK1 activity was measured as described previously with slight modifications (7). Briefly, phosphate-buffered saline-washed cells were trypsinized, lysed, and differentially centrifuged to isolate the cytosolic fractions. Samples were mixed with an equal volume of reaction buffer containing $\left[\right.$ methyl $-^{3} \mathrm{H}$ ] thymidine followed by incubation at $37^{\circ} \mathrm{C}$ with gentle stirring. The slope of the timeactivity curve was used to calculate the number of picomoles of phosphorylated thymidine $/ \mathrm{min} / \mu \mathrm{g}$ protein $(\mathrm{pmol} / \mathrm{min} / \mu \mathrm{g})$.

Immunoblot analysis. SDS-polyacrylamide gel electrophoresis and immunoblot analysis were performed as described (7). Multiple analyses were performed with different sets of samples. Changes in expression levels were determined by scanning densitometry using Universal Hood II (Bio-Rad) and Quantity One software and normalized relative to the level of $\beta$-actin expression.

Statistical analysis. Data are expressed as the means \pm SD. The Wilcoxon's signed-rank test and repeated measured ANOVA were used to compare treatments, and the Spearman's correlation coefficient was used to analyze ENT1 activity and $\left[{ }^{3} \mathrm{H}\right] \mathrm{FLT}$ uptake data using the software package SPSS 12.0 ( $r \geq 0.70$, strong correlation; $0.5 \leq r<0.7$, moderately strong correlation; $0.3 \leq \mathrm{r}<0.5$, weak-to-moderate correlation; and $0.1 \leq \mathrm{r}<0.3$, weak correlation) (17). Statistical significance was set at $\mathrm{P}<0.05$ or $\mathrm{P}<0.01$ as indicated in the Results section. Prism software (version 4.03; GraphPad, San Diego, CA) was used for calculation of the $\mathrm{B}_{\max }$ and $\mathrm{Kd}$ by curve fitting according to the equation: $\mathrm{Y}=\mathrm{B}_{\max } \mathrm{x} \mathrm{X} /(\mathrm{Kd}+\mathrm{X})$, where $\mathrm{Y}$ and $X$ are the specific binding and $\left[{ }^{3} \mathrm{H}\right] \mathrm{NBTI}$ concentration in $\mathrm{nmol} / \mathrm{l}$, respectively.

\section{Results}

Screening of 60 cytotoxic agents for ENT1 activity. Screening of 60 cytotoxic agents known to induce apoptosis, inhibit cell cycle progression, increase DNA intercalation, or inhibit DNA metabolism for ENT1 activity was performed using HeLa cells (Table I). As HeLa cells predominantly express the ENT1 rather 
Table I. The cytotoxic agents and their representative targets.

\begin{tabular}{|c|c|}
\hline Agent & Target \\
\hline Altretamine & Antineoplastic \\
\hline 3-Aminobenzamide & Inhibits poly(ADP-ribose) synthetase \\
\hline 4-Amino-1,8-naphthalimide & Inhibits poly(ADP-ribose) polymerase \\
\hline Amsacrine & Inhibits topoisomerase II \\
\hline Ancitabine & Antineoplastic, metabolized to cytarabine \\
\hline Apigenin & $\mathrm{G} 2 / \mathrm{M}$ phase arrest \\
\hline Aurintricarboxylic acid & Inhibits topoisomerase II \\
\hline 5-Azacytidine & Inhibits DNA methyltransferase \\
\hline Azelaic acid & Inhibits mitochondrial oxidoreductases \\
\hline Bay 11-7085 & Inhibits NFKB \\
\hline Benzamide & Inhibits poly(ADP-ribose) synthetase \\
\hline$O^{6}$-Benzylguanine & Inhibits O6-alkylguanine-DNA alkyltransferase \\
\hline$\beta$-Lapachone & Induces apoptosis \\
\hline 5-Bromo-2'-deoxyuridine & Incorporates into DNA \\
\hline Caffeic acid phenethyl ester & Inhibits NFKB \\
\hline (S)-(+)-camptothecin & Inhibits topoisomerase II \\
\hline Carboplatin & Antineoplastic \\
\hline Carmustine & Alkylates DNA; causes interstrand crosslinks \\
\hline CB 1954 & Antineoplastic \\
\hline ССТ007093 & PPM1D inhibitor \\
\hline Chlorambucil & Crosslinks DNA \\
\hline Chloroquine & Binds strongly to double-stranded DNA \\
\hline CHM-1 hydrate & Binds tubulin and inhibits tubulin polymerization \\
\hline Cisplatin & Crosslinks DNA \\
\hline Cyclophosphamide & Crosslinks DNA \\
\hline Cytosine-1- $\beta$-D-arabinofuranoside & Inhibits DNA synthesis \\
\hline Daidzein & Inhibits mitochondrial aldehyde dehydrogenase; G1-phase arrest \\
\hline Ellipticine & Inhibits topoisomerase II \\
\hline Emetine & Inhibits RNA-protein translation \\
\hline Etoposide & Inhibits topoisomerase II \\
\hline $10058-\mathrm{F} 4$ & Inhibits c-Myc-Max interaction; prevents c-Myc target gene transactivation \\
\hline 5-Fluoro-5'-deoxyuridine & Inhibits DNA synthesis \\
\hline 5-Fluorouracil & Inhibits thymidylate synthetase; $\mathrm{S}$ phase arrest \\
\hline Fusidic acid & Inhibits protein synthesis \\
\hline Ganciclovir & Pro-drug nucleoside analogue \\
\hline Gossypol & Inhibits PKC \\
\hline Hydroxyurea & Inactivates ribonucleoside reductase \\
\hline Idarubicin & Inhibits topoisomerase II \\
\hline 1,5-Isoquinolinediol & Inhibits poly(ADP-ribose) synthetase \\
\hline L-Mimosine & Iron chelator that inhibits DNA replication; G1-phase arrest \\
\hline MDL 28170 & Inhibits calpain I and II \\
\hline Melphalan & Crosslinks DNA \\
\hline Methotrexate & Folic acid antagonist \\
\hline Minocycline & Inhibits basement membrane protease \\
\hline m-Iodobenzylguanidine & Inhibits ADP ribosylation, mitochondrial membrane potential \\
\hline Mitoxantrone & Inhibits DNA synthesis \\
\hline Mizoribine & Inhibits inosine monophosphate dehydrogenase; G/S arrest \\
\hline Nimustine & Alkylates DNA \\
\hline PAC-1 & Activates caspase- 3 \\
\hline p-Benzoquinone & Inhibits topoisomerase II \\
\hline Phosphonoacetic acid & Inhibits DNA polymerase \\
\hline Pifithrin- $\mu$ & Inhibits p53 binding to mitochodria, Bcl-xL, and Bcl-2 \\
\hline Pyrocatechol & Causes DNA strand breakage \\
\hline Retinoic acid & Induces caspase-dependent apoptosis \\
\hline Retinoic acid p-hydroxyanilide & Vitamin A acid analogue \\
\hline Ribavirin & Inhibits of inosine monophosphate dehydrogenase \\
\hline Se-(methyl)selenocysteine & Chemopreventive agent \\
\hline SU 9516 & Inhibits cyclin-dependent kinase-2 \\
\hline TG003 & Inhibits cdc2-like kinase \\
\hline
\end{tabular}




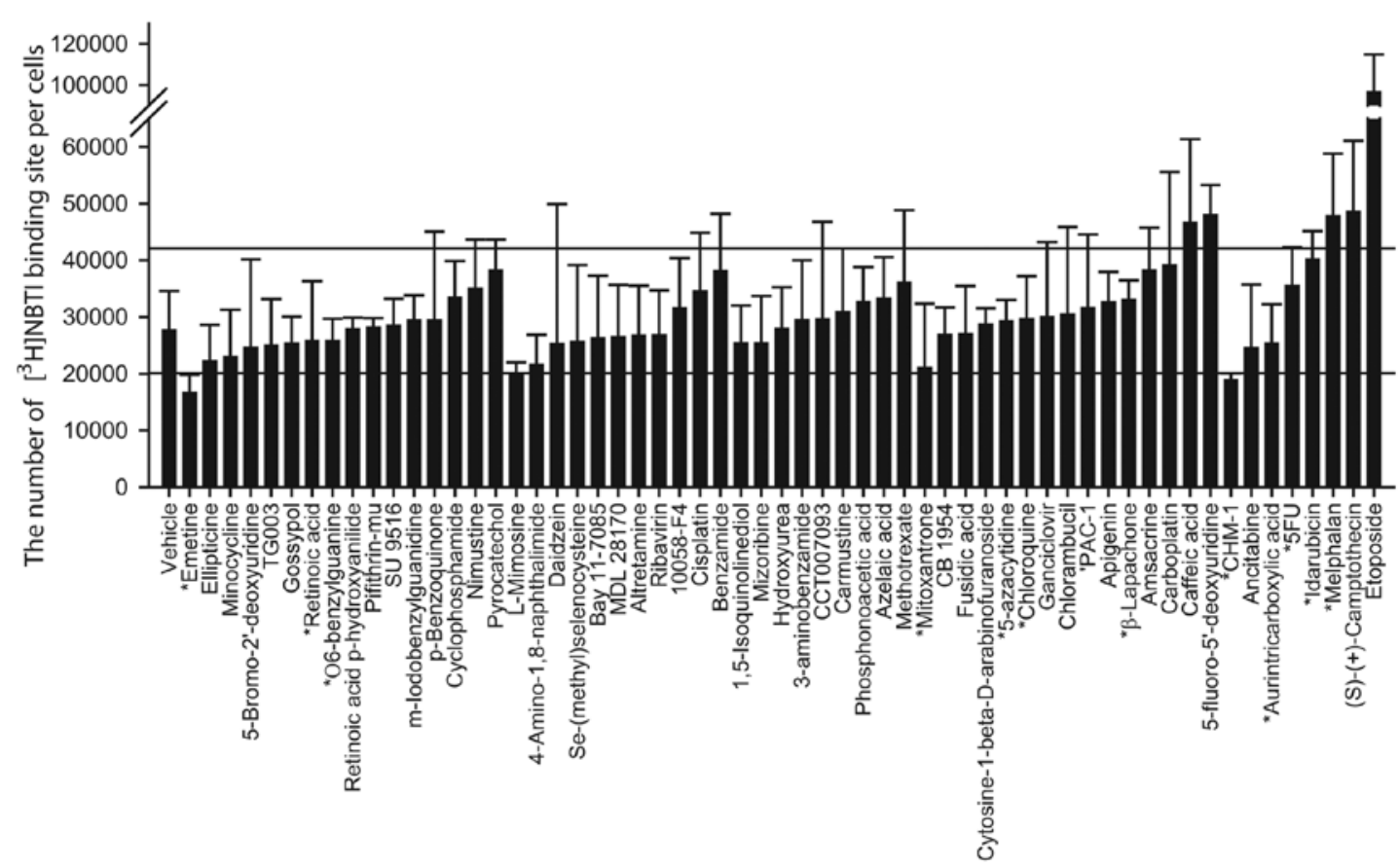

Figure 1. Screening of 60 cytotoxic agents for ENT1 activity and viability in HeLa cells. Cells were exposed to agents that induce apoptosis, inhibit cell cycle progression, increase DNA intercalation, or inhibit DNA repair (Table I) for $24 \mathrm{~h}$ at $10 \mu \mathrm{M}$ (with the exception of $1 \mu \mathrm{M}$ for $\beta$-lapachone, CHM-1 and mitoxantrone; and $0.5 \mu \mathrm{M}$ for idarubicin). The number of $\left[{ }^{3} \mathrm{H}\right] \mathrm{NBTI}$ binding sites/cell was independently measured using vehicle and 5-FU as internal controls. Data are expressed as the means $\pm \mathrm{SD}$, and the lines indicate $\pm 2 \mathrm{SD}$ from vehicle-treated samples. "Agents used in Fig. 3.

than other nucleoside transporter isotypes (14), ENT1 activity is expected to reflect nucleoside dynamics. In general, it is recommended that $\left[{ }^{18} \mathrm{~F}\right]$ FLT-PET not be performed immediately after treatment to avoid off-target effects. Thus, the equilibrative response to agents was evaluated after $24 \mathrm{~h}$ of treatment. Most of the agents studied had a minimal effect on ENT1 activity (Fig. 1). Emetine, ellipticine, and minocycline decreased ENT1 activity by $40 \%$. The agents that increased ENT1 activity by $>2$ standard deviations were 5-FU (DNA metabolism inhibition), melphalan (DNA alkylation), camptothecin (topoisomerase I inhibition), idarubicin (topoisomerase II inhibition), and etoposide (topoisomerase II inhibition).

Changes in the cell viability induced by the 60 cytotoxic agents. Cell viability changes in HeLa cells in response to the screened agents were measured to determine whether the changes in ENT1 activity correlated with cell death. All of the agents were used at the same concentrations as indicated in Fig. 1, and were incubated with the cells for $72 \mathrm{~h}$. Of the compounds tested, $12 \%$ reduced the relative cell viability by $>60 \%, 24 \%$ reduced the relative viability by between 20 and $60 \%$, and $64 \%$ reduced relative viability by $<20 \%$ (Fig. $2 \mathrm{~A}$ ). Plotting the relative cell viability vs. ENT1 activity revealed that the two parameters showed no correlation (Fig. 2B).

Changes in $\left[{ }^{3} H\right] F L T$ uptake correlate with ENT1 activity. Uptake changes for $\left[{ }^{3} \mathrm{H}\right] \mathrm{FLT}$ were examined to investigate whether the changes in ENT1 activity by pharmacologically active agents influence $\left[{ }^{18} \mathrm{~F}\right] \mathrm{FLT}$-PET. We randomly selected 14 agents and measured $\left[{ }^{3} \mathrm{H}\right] \mathrm{FLT}$ uptake after $24 \mathrm{~h}$ of exposure (Fig. 3A). Drug treatment changed $\left[{ }^{3} \mathrm{H}\right]$ FLT uptake from -16 to $111 \%$ compared with vehicle treatment. $\left[{ }^{3} \mathrm{H}\right] \mathrm{FLT}$ uptake was highly correlated with the relative changes in ENT1 activity (Spearman's correlation coefficient, $r=0.66 ; \mathrm{P}<0.01$ ) (Fig. 3B)

Confirmation of etoposide-induced ENT1 activity and uptake of $\left[{ }^{3}\right.$ H]FLT in HeLa, HT29 and MDA-MB-231 cells. As etoposide effectively increased ENT1 activity in the screening (Fig. 1), we confirmed the effect of etoposide in HT29 cells (a ENT1-low expressing cell line) and MDA-MB-231 cells (a ENT1-high expressing cell line) (18). We confirmed the concentration of ligand required to reach half maximal binding ( $\mathrm{Kd}$, affinity) and the maximal binding $\left(\mathrm{B}_{\max }\right.$, the number of transporters) in our systems and calculated these values as 1.626 and 188,587 for MDA-MB-231 cells, 0.808 and 60,996 for HeLa cells, and 0.643 and 46,111 for HT29 cells, respectively (Fig. 4A). The number of $\left[{ }^{3} \mathrm{H}\right] \mathrm{NBTI}$ binding sites/cell increased 3.45 and 2.83 times after etoposide treatment in HT29 and MDA-MB-231 cells, respectively (Fig. 4B) $(\mathrm{P}<0.05)$. In parallel, the basal level (vehicle-treated) of $\left[{ }^{3} \mathrm{H}\right]$ FLT uptake was higher in MDA-MB231 cells than in HT29 cells. Treatment with etoposide for $24 \mathrm{~h}$ induced the increase in $\left[{ }^{3} \mathrm{H}\right] \mathrm{FLT}$ uptake by $49 \%$ in HT2 9 cells and $38 \%$ in MDA-MB-231 cells (Fig. 4C) $(\mathrm{P}<0.05)$, which was correlated with a change in ENT1 activity.

Etoposide-induced cell cycle changes in HeLa, HT29 and MDA-MB-231 cells. In order to investigate the molecular mechanism for the increase in ENT1 activity by etoposide, we measured the etoposide-induced effect on the cell cycle. Etoposide significantly increased the fraction of HeLa, HT29 and MDA-MB-231 cells in the S and G2M phases by 2 -fold after $24 \mathrm{~h}$ of treatment (Fig. 5A) accompanied by an increase in TK1 activity (Fig. 5B) $(\mathrm{P}<0.05$ for HT29 cells; $\mathrm{P}<0.01$ for 

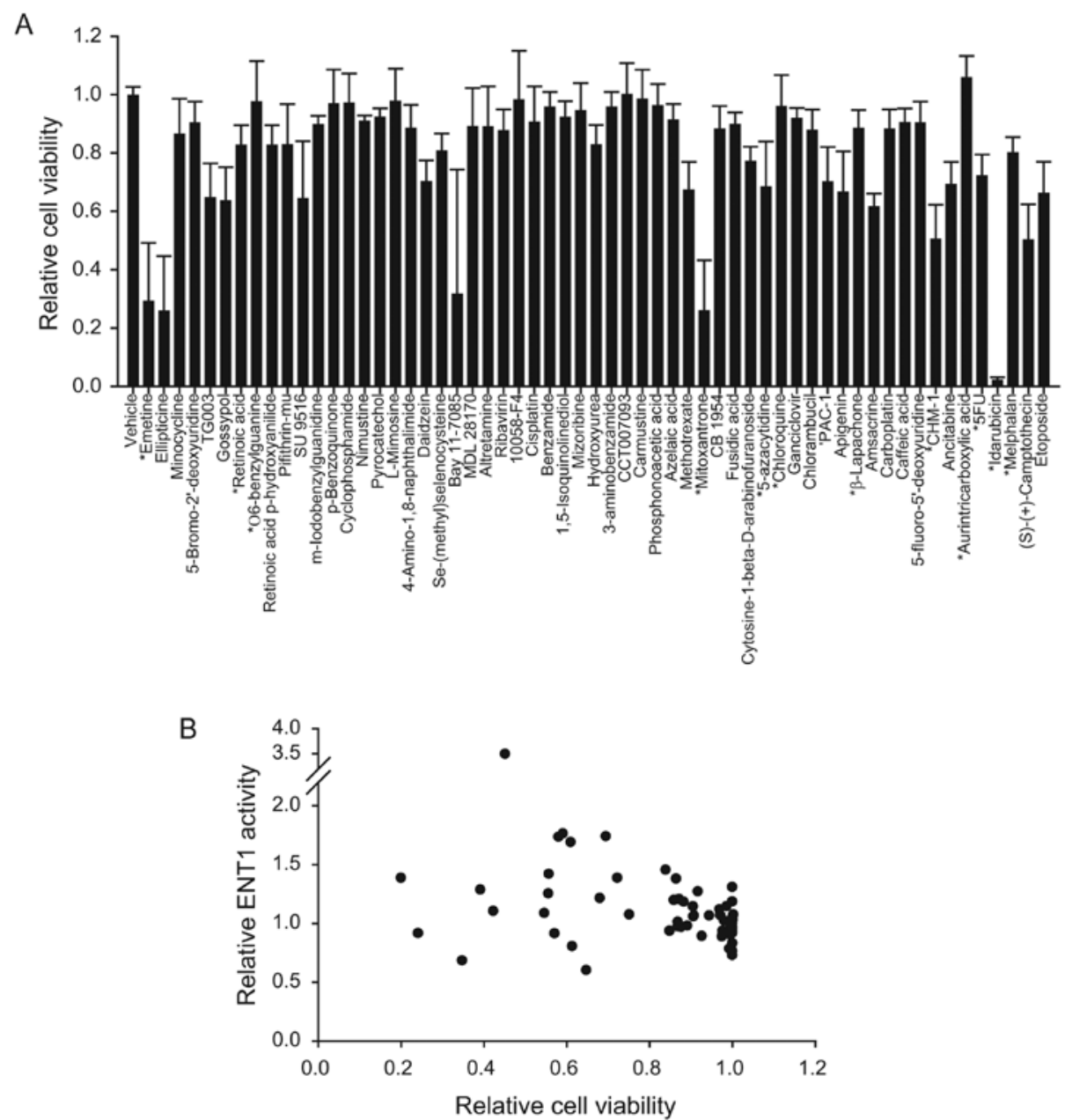

Figure 2. Screening of 60 cytotoxic agents for changes in the viability of HeLa cells. (A) Cells were exposed to the indicated agents for $72 \mathrm{~h}$ and cell viability was measured using an MTS assay ( $\mathrm{n}=3$ ). Data are expressed as the means \pm SD. (B) Relative viability was plotted against relative ENT1 activity at $24 \mathrm{~h}$ using data from Fig. 1 .

A

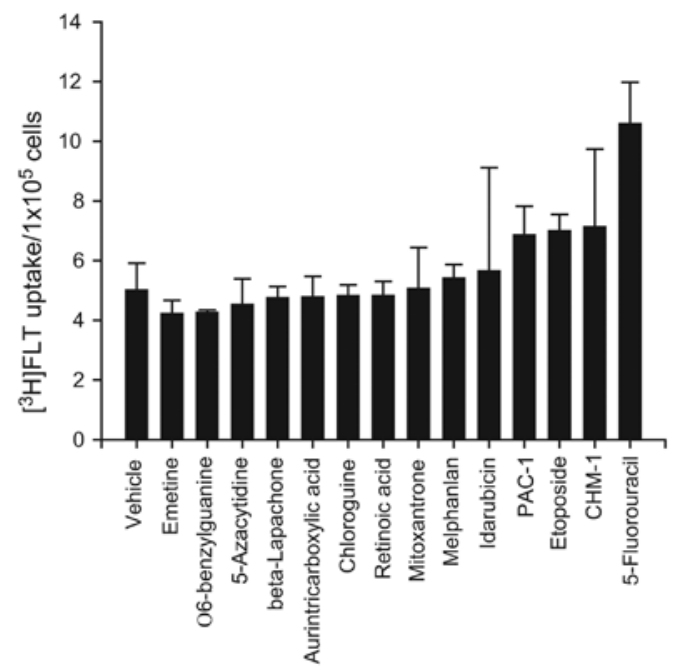

B

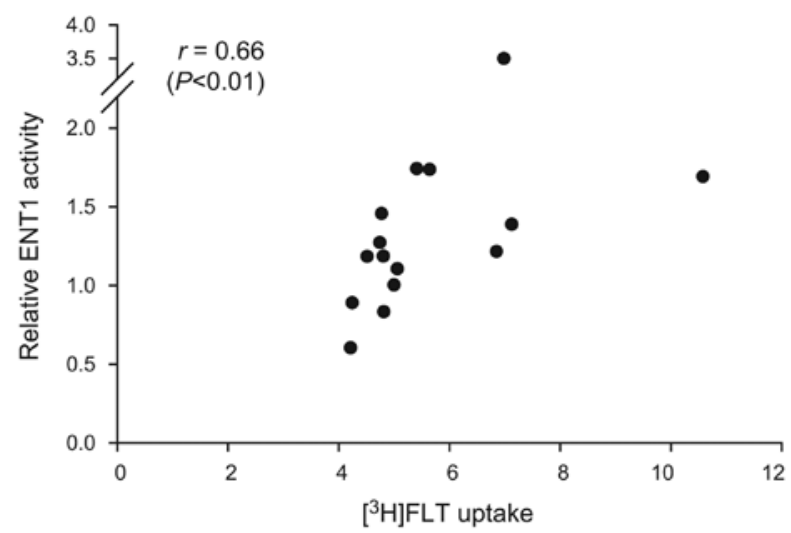

Figure 3. Changes in $\left[{ }^{3} \mathrm{H}\right] \mathrm{FLT}$ uptake in relation to ENT1 activity. (A) Cells were exposed to 14 cytotoxic agents from Fig. 1 for $24 \mathrm{~h}$. After incubation with $\left[{ }^{3} \mathrm{H}\right]$ FLT in fresh media for an additional $2 \mathrm{~h}$, the uptake of $\left[{ }^{3} \mathrm{H}\right] \mathrm{FLT}$ was determined and normalized to $1 \times 10^{6} \mathrm{cells}(\mathrm{n}=4)$. Data are expressed as the means $\pm \mathrm{SD}$. (B) $\left[{ }^{3} \mathrm{H}\right]$ FLT uptake was plotted against relative ENT1 activity from Fig. 1. Spearman correlation coefficient (r) and P-value are shown.

MDA-MB-231 cells). Time-dependent analysis showed that TK1 expression significantly increased at $24 \mathrm{~h}$ in HeLa and
HT29 cells, and remained elevated until 48 h post-stimulation (Fig. 5C). The expression of cyclin A was slightly increased by 
A

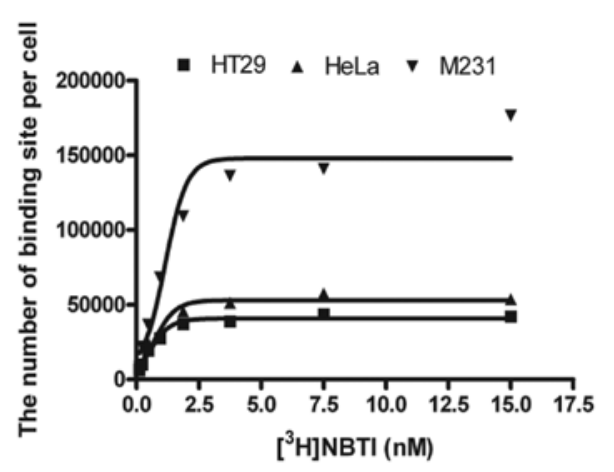

B

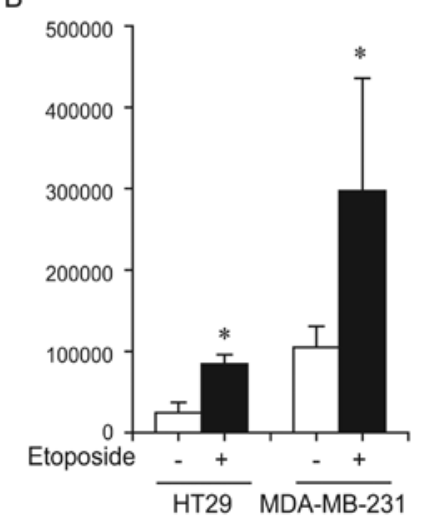

C

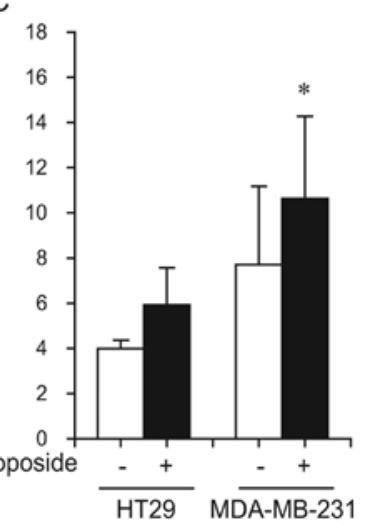

Figure 4. Etoposide-induced changes in ENT1 activity and $\left[{ }^{3} \mathrm{H}\right] \mathrm{FLT}$ uptake in HeLa, HT29 and MDA-MB-231 cells. (A) Exponentially growing cells were trypsinized and incubated with various concentrations of $\left[{ }^{3} \mathrm{H}\right] \mathrm{NBTI}$ either with or without $20 \mu \mathrm{M}$ NBTG. The number of specific binding sites for $\left[{ }^{3} \mathrm{H}\right] \mathrm{NBTI} / \mathrm{cell}$ was determined. Results were independently confirmed and a representative one is shown. (B and C) Cells were exposed to vehicle or $10 \mu \mathrm{M}$ etoposide for $24 \mathrm{~h}$ and were subjected to measurement of ENT1 activity with (B) $0 \mathrm{nM}\left[{ }^{3} \mathrm{H}\right] \mathrm{NBTI}$ or $(\mathrm{C})\left[{ }^{3} \mathrm{H}\right] \mathrm{FLT}$ uptake. Data are expressed as the means $\pm \mathrm{SD}$. ${ }^{*} \mathrm{P}<0.05$ compared with vehicle-treated samples.

etoposide in HeLa cells, whereas it was significantly increased in HT29 cells.

Combination effect of ENT1 inhibitors on etoposide-induced cytotoxicity in HeLa, HT29 and MDA-MB-231 cells. In order to apply ENT1-mediated $\left[{ }^{18} \mathrm{~F}\right] \mathrm{FLT}$ flare to monitor therapeutic response, the mechanism for ENT1 activation should be related with the cell death pathway. We hypothesized that the inhibition of ENT1 activity may affect etoposide-induced cytotoxicity when the increase in ENT1 activity by etoposide contributes to the increase in salvage capacity and resistance mechanism. We monitored the etoposide-induced cell viability with dipyridamol or NBTI, inhibitors for the nucleoside transporter, after a 72-h treatment (Fig. 6). Etoposide dose-dependently decreased cell viability in three cell lines $(\mathrm{P}<0.05)$. The maximum cytotoxic effect was highest in HT29 cells with $41.3 \%$. The HeLa cells treated with dipyridamol or NBTI alone showed a slight decrease in viability. The HeLa cells that were co-treated with dipyridamol or NBTI did not show a dose-dependent cytotoxic effect for etoposide, suggesting the possibility that the inhibitors repress the dose-dependent cytotoxic effect of etoposide or that the cytotoxic effect of the inhibitor is dominant over that of etoposide. However, dipyridamol or NBTI did not

exhibit any changes in etoposide-induced cell death in the HT29 and MDA-MB-231 cells. These results indicate that the role of ENT1 activation by etoposide is cell type-dependent and could be downstream from the pathway that is subordinate or irrelevant to cell death.

\section{Discussion}

A recent study showed that various cytotoxic drugs induce $\left[{ }^{18} \mathrm{~F}\right] \mathrm{FLT}$ flare, which raises caution concerning the schedule of dosing and imaging. ENT1 is a part of the salvage pathway for DNA synthesis and is an indispensable mediator of FLT transportation. However, extensive screening for the pharmacological regulation of ENT1 activity in relation to $\left[{ }^{18} \mathrm{~F}\right]$ FLT flare has not yet been performed. In this study, we identified ENT1 modulators by screening 60 cytotoxic agents, and showed that pharmacological agent-induced changes in ENT1 activity correlate with $\left[{ }^{3} \mathrm{H}\right] \mathrm{FLT}$ uptake. We specifically confirmed that etoposide-induced increases in ENT1 activity were due to cell cycle arrest in the proliferation phase.

To date, no adequate assay system for evaluating ENT1 activity on a large scale has been established, which has limited the availability of information regarding the regulation of ENT1. A previous study of ENT1 activity induced by 22 protein kinase inhibitors conducted by the Graves group used a $\left[{ }^{3} \mathrm{H}\right]$ uridine uptake assay (16). This assay has advantages in that it is simple and only a small number of cells are required. However, it was not suitable for our screening, as the incubation time for $\left[{ }^{3} \mathrm{H}\right]$ uridine uptake assay is approximately $30 \mathrm{sec}$ and a large number of samples could provoke prolonged washout time leading to $\left[{ }^{3} \mathrm{H}\right]$ uridine efflux into the media. In this study, we adopted a $\left[{ }^{3} \mathrm{H}\right] \mathrm{NBTI}$ binding assay as NBTI inhibits selective $\left[{ }^{3} \mathrm{H}\right] \mathrm{NBTI}$ binding to ENT1 in the plasma membrane and we could stably analyze up to 10 agents at once. In all sets, vehicle and 5-FU were included as internal controls. However, the method still has some limitations in that the standard deviation was relatively high. The values for vehicle- and 5-FU-treated samples were 27,606.4 $\pm 6,948.4$ and $46,595.8 \pm 14,776.0$, respectively. Given that the ideal assay for screening has a $\mathrm{Z}$ factor $>0.5$ (19), the overlap between the positive and the negative controls makes it difficult to identify agents that induce ENT1 activity to a lesser extent than 5-FU. This may be due to the fact that the $\left[{ }^{3} \mathrm{H}\right] \mathrm{NBTI}$ binding assay requires multiple steps for each individual sample. The development of a more accurate assay system, such as a 96-well plate-based ligand binding assay, would allow confirmation of the present findings.

Our data demonstrated for the first time that topoisomerase I/II inhibitors such as aurintricarboxylic acid, idarubicin, camptothecin and etoposide potently increase ENT1 activity at a level comparable with, or higher than, 5-FU. The increase in ENT1 activity mediated by etoposide was confirmed in MDA-MB-231 and HT29 cells. Yet, not all of the topoisomerase inhibitors altered ENT1 activity (amsacrine, ellipticine, and p-benzoquinone). Similarly, some antimetabolites minimally changed ENT1 activity within a 2 SD variation (ribavirin, methotrexate and ganciclovir) in contrast to 5-FU. In addition, the inducers for cell cycle at $\mathrm{S}$ phase such as hydroxyurea (21) and mizoribine (22) did not increase ENT1 activity in this system. It is thought that the potency or duration of ENT1 

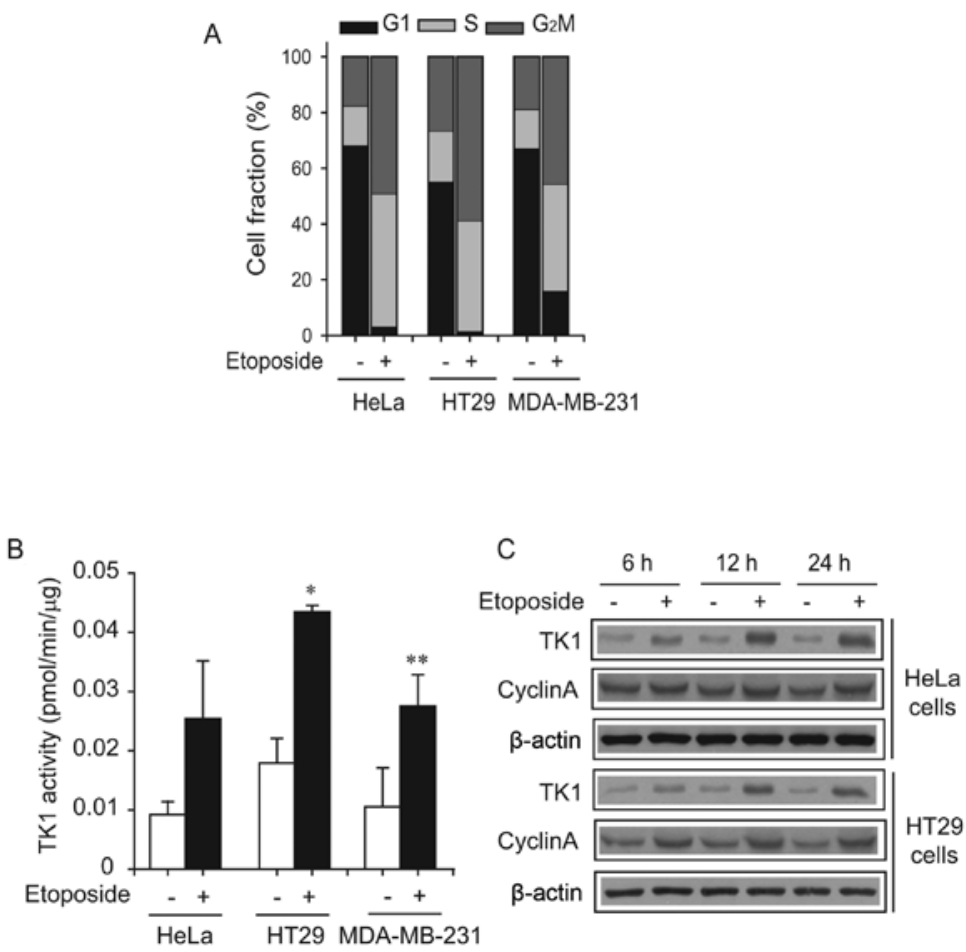

Figure 5. Cell cycle changes in HeLa, HT29 and MDA-MB-231 cells by etoposide. Cells were treated with vehicle or $10 \mu \mathrm{M}$ etoposide for $24 \mathrm{~h}$ and subjected to the measurement of the cell cycle distribution by propidium iodide staining (A) and TK1 activity (B). Time-dependent changes in TK1 and cyclin A expression were monitored after incubation of cells with vehicle (-) or $10 \mu \mathrm{M}$ etoposide (+) for 6,24 or $48 \mathrm{~h}$ by immunoblot analysis (C). All experiments were independently repeated 3 times. Data are expressed as the mean $\pm \mathrm{SD} .{ }^{*} \mathrm{P}<0.05 ;{ }^{* *} \mathrm{P}<0.01$ compared with vehicle-treated samples.

A

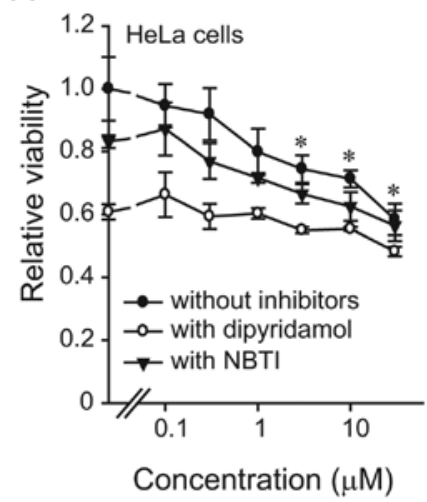

B

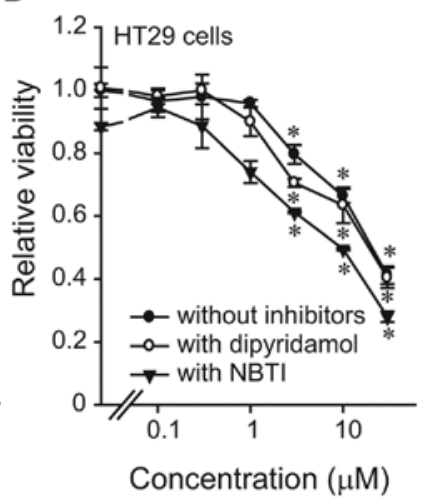

C

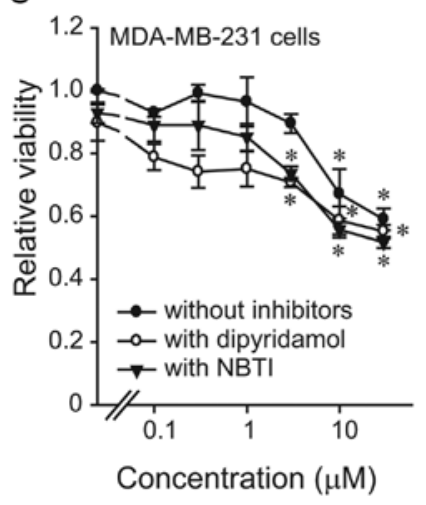

Figure 6. Effect of the combination of etoposide with ENT1 inhibitors on the cell viability of HeLa, HT29 and MDA-MB-231 cells. Cells were exposed to etoposide at a concentration of $0,0.1,0.3,1,3,10$, or $30 \mu \mathrm{M}$, without inhibitors (black circle), with $10 \mu \mathrm{M}$ dipyridamol (white circle) or $10 \mu \mathrm{M}$ NBTI (black triangle) for $72 \mathrm{~h}$. The viability was measured with MTS assay. All experiments were repeatedly confirmed. Data are expressed as the means \pm SD. ${ }^{*} \mathrm{P}<0.05$ compared with the samples treated with $0 \mu \mathrm{M}$ etoposide (DMSO only) for each treated group.

activation by each agent would be different as we used a fixed concentration for screening and obtained various ranges of cytotoxicity (Fig. 2). When agents are used at the isotoxic dose in each cell lines it is expected that they produce a similar tendency for ENT1 activation.

The possibility has been raised that $\left[{ }^{18} \mathrm{~F}\right] \mathrm{FLT}$ flare could be used for the treatment monitoring of the thymidylate synthase inhibitor $(3,20)$. However it has never been examined whether $\left[{ }^{18} \mathrm{~F}\right] \mathrm{FLT}$ flare reflects the degree of treatment response. Our results showed that ENT1 activity did not correlate with cell viability measured by MTS, but highly correlated with $\left[{ }^{3} \mathrm{H}\right] \mathrm{FLT}$ uptake based on the data from 14 randomly selected agents (Figs. 2 and 3). The increase in ENT1 activity may contribute to the influx of thymidine into the cytoplasm, the increase in salvage capacity, and eventually treatment failure. Our study on etoposide revealed that etoposide-induced ENT1 activation was cell-type dependent (Fig. 6). In HeLa cells, the blocking of ENT1 activity repressed etoposide-induced cell death in HeLa cells, indicating ENT1 activation contributes to an etoposideinduced mechanism for HeLa cell death. In contrast, ENT1 inhibitors had no effect on etoposide-induced cell death in HT29 and MDA-MB-231 cells, suggesting that the pathway 
for ENT1 activation may be irrelevant to cell death. If anticancer agents may affect ENT1 activity independent of the cell death pathway, FLT uptake may not reflect anticancer agentinduced changes in cell viability. Therefore, it would be better to monitor the effect of anticancer agents after a prolonged period of exposure to avoid the ENT1-mediated effect on FLT uptake. Additionally, the kinetics of ENT1 activity induced by anticancer agents should be carefully investigated.

Our studies found that the modulation of ENT1 activity by pharmacological agents is closely related to $\left[{ }^{3} \mathrm{H}\right] \mathrm{FLT}$ uptake. Furthermore, we demonstrated that etoposide is a potent inducer of ENT1 activity, which is accompanied by an increase in TK1 activity and $\left[{ }^{3} \mathrm{H}\right] \mathrm{FLT}$ flare. This study provides valuable information regarding the possible application of FLT-PET for etoposide-based chemotherapy.

\section{Acknowledgements}

This study was supported by a grant from the Korea Healthcare Technology R\&D Project of the Ministry for Health, Welfare, and Family Affairs, Republic of Korea (A101187). The authors thank H.J. Lee for her help with this study.

\section{References}

1. Shields AF, Grierson JR, Dohmen BM, et al: Imaging proliferation in vivo with [F-18]FLT and positron emission tomography. Nat Med 4: 1334-1336, 1998.

2. Dittmann H, Dohmen BM, Kehlbach R, et al: Early changes in [18F]FLT uptake after chemotherapy: an experimental study. Eur J Nucl Med Mol Imaging 29: 1462-1469, 2002

3. Kenny LM, Contractor KB, Stebbing J, et al: Altered tissue 3'-deoxy-3'-[18F]fluorothymidine pharmacokinetics in human breast cancer following capecitabine treatment detected by positron emission tomography. Clin Cancer Res 15: 6649-6657, 2009.

4. Pillai RG, Forster M, Perumal M, et al: Imaging pharmacodynamics of the alpha-folate receptor-targeted thymidylate synthase inhibitor BGC 945. Cancer Res 68: 3827-3834, 2008.

5. Pressacco J, Wiley JS, Jamieson GP, Erlichman C and Hedley DW: Modulation of the equilibrative nucleoside transporter by inhibitors of DNA synthesis. Br J Cancer 72: 939-942, 1995.

6. Pressacco J, Mitrovski B, Erlichman C and Hedley DW: Effects of thymidylate synthase inhibition on thymidine kinase activity and nucleoside transporter expression. Cancer Res 55: 1505-1508, 1995.

7. Lee SJ, Kim SY, Chung JH, Oh SJ, et al: Induction of thymidine kinase 1 after 5-fluorouracil as a mechanism for 3'-deoxy-3'-[18F fluorothymidine flare. Biochem Pharmacol 80: 1528-1536, 2010.
8. Perumal M, Pillai RG, Barthel H, et al: Redistribution of nucleoside transporters to the cell membrane provides a novel approach for imaging thymidylate synthase inhibition by positron emission tomography. Cancer Res 66: 8558-8564, 2006.

9. Cruet-Hennequart S, Villalan S, Kaczmarczyk A, O'Meara E Sokol AM and Carty MP: Characterization of the effects of cisplatin and carboplatin on cell cycle progression and DNA damage response activation in DNA polymerase eta-deficient human cells. Cell Cycle 8: 3039-3050, 2009.

10. Yau K, Price P, Pillai RG and Aboagye E: Elevation of radiolabelled thymidine uptake in RIF-1 fibrosarcoma and HT29 colon adenocarcinoma cells after treatment with thymidylate synthase inhibitors. Eur J Nucl Med Mol Imaging 33: 981-987, 2006.

11. Paproski RJ, Ng AM, Yao SY, Graham K, Young JD and Cass CE: The role of human nucleoside transporters in uptake of 3'-deoxy3'-fluorothymidine. Mol Pharmacol 74: 1372-1380, 2008.

12. King AE, Ackley M, Cass CE, Young JD and Baldwin SA: Nucleoside transporters: from scavengers to novel therapeutic targets. Trends Pharmacol Sci 27: 416-425, 2006.

13. Cass CE, Dahlig E, Lau EY, Lynch TP and Paterson AR: Fluctuations in nucleoside uptake and binding of the inhibitor of nucleoside transport, nitrobenzylthioinosine, during the replication cycle of HeLa cells. Cancer Res 39: 1245-1252, 1979.

14. Coe I, Zhang Y, McKenzie T and Naydenova Z: PKC regulation of the human equilibrative nucleoside transporter, hENT1. FEBS Lett 517: 201-205, 2002.

15. Huang M, Wang Y, Collins M, Gu JJ, Mitchell BS and Graves LM: Inhibition of nucleoside transport by p38 MAPK inhibitors. J Biol Chem 277: 28364-28367, 2002.

16. Huang M, Wang Y, Cogut SB, Mitchell BS and Graves LM: Inhibition of nucleoside transport by protein kinase inhibitors. J Pharmacol Exp Ther 304: 753-760, 2003.

17. Grem JL, Danenberg KD, Behan K, et al: Thymidine kinase, thymidylate synthase, and dihydropyrimidine dehydrogenase profiles of cell lines of the National Cancer Institute's Anticancer Drug Screen. Clin Cancer Res 7: 999-1009, 2001.

18. Lu X, Gong S, Monks A, Zaharevitz D and Moscow JA: Correlation of nucleoside and nucleobase transporter gene expression with antimetabolite drug cytotoxicity. J Exp Ther Oncol 2: 200-212, 2002

19. Zhang JH, Chung TD and Oldenburg KR: A simple statistical parameter for use in evaluation and validation of high throughput screening assays. J Biomol Screen 4: 67-73, 1999.

20. Plotnik DA, McLaughlin LJ, Krohn KA and Schwartz JL: The effects of 5-fluoruracil treatment on 3'-fluoro-3'-deoxythymidine (FLT) transport and metabolism in proliferating and non-proliferating cultures of human tumor cells. Nucl Med Biol: May 4, 2012 (Epub ahead of print)

21. Liu L, Choi JH, Yim H, Choi JS, Park BD, Cho SJ and Lee SK: ATR (AT mutated Rad3 related) activity stabilizes Cdc6 and delays G2/M-phase entry during hydroxyurea-induced S-phase arrest of HeLa cells. Int J Biochem Cell Biol 41: 1410-1420, 2009.

22. Liu S, Xie Y, Lv Y, et al: A novel target of mizoribine inhibiting mesangial cell proliferation: $S$ phase kinase-associated protein 2 . Am J Nephrol 32: 447-455, 2010. 